\title{
Home Visit: Strategi PAUD dari Rumah bagi Guru di Daerah 3T pada Masa Pandemi Covid-19
}

\author{
Besse Nirmala $^{\circledR}$, Haerul Annuar ${ }^{2}$ \\ Pendidikan Guru Pendidikan Anak Usia Dini, Universitas Tadulako \\ DOI: $\underline{10.31004 / o b s e s i . v 5 i 2.716}$
}

\begin{abstract}
Abstrak
Provinsi Sulawesi Tengah menduduki urutan ketiga yang memiliki daerah 3T terbanyak seIndonesia. Fasilitas penunjang proses pembelajaran dari rumah di masa pandemi covid-19 menjadi keterbatasan bagi guru 3T. Tujuan dari penelitian ini yaitu untuk menganalisis strategi home visit yang dilakukan oleh guru sebagai implementasi PAUD dari rumah di daerah 3T pada masa pandemi covid-19. Penelitian ini menggunakan mix method yaitu menggabungkan antara penelitian kuantitatif dan kualitatif. Sampel terdiri dari 235 orang guru TK, KB, dan SPS yang ada di Kabupaten Sigi. Teknik pengumpulan data dilakukan dengan menyebarkan angket. Peneliti juga menggunakan daftar wawancara dan dokumentasi sebagai data pendukung. Teknik analisis data dengan menggunakan Miles \& Hubberman. Hasil penelitian menunjukkan sekitar $84,3 \%$ guru mengimplementasikan strategi home visit sebagai pembelajaran pada masa pandemi. Adapun tahapannya yakni: 1) tahap persiapan; 2) tahap pelaksanaan; 3) tahap kegiatan lanjutan; dan 4) tahap monitoring dan evaluasi. Strategi home visit ini menjadi solusi bagi guru PAUD dengan segala keterbatasan agar tetap memberikan layanan yang terbaik untuk anak usia dini di daerah 3T.
\end{abstract}

Kata Kunci: home visit; paud; daerah $3 t$.

\begin{abstract}
Central Sulawesi Province ranks third with the most 3T areas in Indonesia. Facilities to support the learning from home during the Covid-19 pandemic have become a limitation for 3T teachers. The purpose of this study was to analyze the home visit strategy carried out by teacher as the implementation of early childhood education from home in the 3T area during the Covid19 pandemic. This study uses a mic method which combines quantitative and qualitative research. The sample consisted of 235 teachers from kindergarten, playgroup, and similar PAUD units in Sigi Regency. The data collection technique was carried out by distributing questionnaires. Researchers also used a list of interviews and documentation as supporting data. Data analysis techniques using Miles \& Hubberman. The results showed that around $84.3 \%$ of teachers implemented home visit strategy as learning during a pandemic. As for the stages, namely: 1) the preparation stage; 2 ) implementation stage; 3 ) the follow-up activity stage; and 4) the monitoring and evaluation stage. This home visit strategy is a solution for ECE teachers with all their limitations to continue provide the best service for early childhood in the $3 \mathrm{~T}$ area.
\end{abstract}

Keywords: home visit; ece; 3 t area.

Copyright (c) 2020 Besse Nirmala, Haerul Annuar

$\triangle$ Corresponding author :

Email Address : bessenirmala@rocketmail.com (Palu, Sulawesi Tengah)

Received 13 August 2020, Accepted 20 September 2020, Published 25 September 2020 


\section{PENDAHULUAN}

Coronavirus Disease 2019 atau yang lebih dikenal dengan sebutan Covid-19 telah menginfeksi ribuan orang diberbagai negara di dunia sehingga menyebabkan banyak kematian (Shereen et al., 2020; Lin \& Bates, 2010). Covid-19 ini pertama kali muncul di Kota Wuhan, Provinsi Hubei, China (Shi et al., 2020) dan telah ditetapkan sebagai pandemi global (Sohrabi et al., 2020). Covid-19 ini menjadi ancaman yang dapat menyerang siapa saja. Oleh karena itu, sejak pertengahan Maret 2020, pemerintah Indonesia menerapkan kebijakan belajar dari rumah, bekerja dari rumah, dan beribadah di rumah.

Sebagai upaya mencegah perluasan penularan Covid-19 khususnya pada bidang pendidikan, Menteri Pendidikan dan Kebudayaan menerbitkan surat edaran Nomor 4 Tahun 2020 tentang pelaksanaan dalam masa darurat Covid-19 yakni: 1) belajar dari rumah melalui pembelajaran dalam jaringan (daring) dilaksanakan untuk memberikan pengalaman belajar yang bermakna bagi anak tanpa terbebani dengan tuntutan dan mengharuskan anak menuntaskan seluruh capaian kurikulum untuk kenaikan kelas atau kelulusan; 2) belajar dari rumah dapat difokuskan pada pendidikan kecakapan hidup antara lain mengenai pandemik Covid-19; 3) aktivitas dan tugas pembelajaran dari rumah dapat bervariasi antar anak, sesuai minat dan kondisi masing-masing, termasuk mempertimbangkan kesenjangan akses/fasilitas belajar di rumah; dan 4) bukti atau produk aktivitas belajar dari rumah diberi umpan balik yang bersifat kualitatif dan berguna dari guru (Kemdikbud, 2020). Kementerian agama juga mengeluarkan kebijakan tentang mekanisme pembelajaran dan penilaian madrasah pada masa darurat penyebaran Covid-19 dengan memanfaatkan berbagai plaform e-learning, (Mekanisme Pembelajaran Dan Penilaian Madrasah Dalam Masa Darurat Pencegahan Penyebaran Covid-19, 2020). Kebijakan ini dikeluarkan karena kebijakan penyelenggaraan pendidikan melalui tatap muka tidak bisa dilaksanakan dalam situasi pandemi, (Nurkolis \& Muhdi, 2020; (Sun et al., 2020).

Menteri Pendidikan memberi kebijakan terkait penyelenggaraan kegiatan belajar mengajar dilakukan di rumah masing-masing dengan menggunakan sistem dalam jaringan (daring). Kemajuan teknologi dan informasi pada masa digital mendorong guru harus menerapkan pembelajaran dengan cara daring/online. Tentunya dalam mengimplementasi pembelajaran daring/online diperlukan sarana dan prasarana pendukung yakni kesiapan sumber daya manusia, dukungan teknologi berupa smartphone atau laptop, jaringan internet, kuota/data, dan listrik. Hal ini juga diperkuat oleh hasil penelitian (Agus Purwanto*, Rudy Pramono, Masduki Asbari, Priyono Budi Santoso, Laksmi Mayesti Wijayanti, Choi Chi Hyun, 2017) bahwa ada beberapa kendala yang dialami oleh guru, siswa, dan orang tua dalam pembelajaran daring yaitu biaya kuota internet yang tidak terjangkau, jaringan internet yang terbatas beban kinerja guru terlalu banyak dan penguasaan teknologi informasi baik dari guru maupun orang tua yang masih sangat kurang. Oleh karena itu, kondisi tersebut belum sepenuhnya mendukung pembelajaran daring/online khususnya di Provinsi Sulawesi Tengah.

Provinsi Sulawesi Tengah menduduki urutan ketiga yang mempunyai daerah 3T (Terdepan, Terpencil, dan Tertinggal) yang terbanyak se-Indonesia. Sembilan daerah 3T tersebut yakni Kabupaten Sigi, Banggai Kepulauan, Donggala, Toli-toli, Buol, Parigi Moutong, Tojo Una-una, Banggai Laut, dan Kabupaten Morowali Utara, (Nugracha, 2019). Guru yang ada di daerah 3T tersebut mengalami kesulitan dalam mengimplementasikan belajar dari rumah melalui pembelajaran daring/online. Hal ini karena di daerah tersebut minim fasilitas, terutama jaringan internet. Selain itu, beberapa kendala yang dialami guru-guru di daerah 3T yaitu kualifikasi dan kompetensi pendidikan yang rata-rata masih minim (berijazah SMA atau sederajat), infrastruktur sekadarnya, dan minimnya jumlah tenaga pendidik (Putra \& Rhussary, 2014). Selain itu, pembelajaran daring yang sudah diterapkan bagi anak usia dini dibeberapa daerah mempengaruhi pencapaian perkembangan anak usia dini. Hal tersebut berdasarkan hasil penelitian menunjukkan sebagai besar pencapaian perkembangan anak dari 
berbagai aspek mengalami penurunan. Hal ini menjadi bahan untuk mengevaluasi pelaksanaan pembelajaran daring di lembaga PAUD, (Wulandari \& Purwanta, 2021).

Berbagai kendala tersebut tidak menghalangi tenaga pendidik khususnya guru Pendidikan Anak Usia Dini (PAUD) yang ada di daerah 3T untuk terus memberikan asupan stimulasi bagi tumbuh kembang anak. Salah satunya pembelajaran yang dilakukan guru di daerah 3T ditengah pandemi Covid-19 ini yaitu strategi home visit. Strategi home visit merupakan upaya guru yang ada di daerah 3T dalam rangka menstimulasi anak dari rumah. Howard, K.S., dan Jeanne Brooks-Gunn (2009) mengembangkan program home visit untuk anak dari keluarga yang kurang mampu/kurang sejahtera dalam rangka memberikan stimulasi sejak usia dini (Komalasari, 2016). Hal ini juga menjadi solusi ketika anak mulai jenuh dan rindu akan sosok seorang guru. Kegiatan home visit ini juga diharapkan mampu memberikan pelayanan yang terbaik untuk anak selama masa pandemi Covid-19 bagi keluarga dengan segala keterbatasan asesibilitas.

Beberapa hasil penelitian terkait implementasi strategi home visit pada masa pandemi Covid-19 menunjukkan dampak yang positif dan signifikan terselenggaranya proses pembelajaran di rumah (Nahdi et al., 2020). Hasil penelitian dari (Ilhan et al., 2019) "home visits and family engagement have positive impacts on students academic achievements and attitudes in school. The results of the study are applicable broadly in education and can assist teachers in improving the academic performance of their students. Penelitian tersebut menunjukkan bahwa home visit memiliki dampak positif pada keberhasilan akademik khususnya aspek pencapaian perkembangan anak usia dini. Selain itu, hasil penelitian dari (Leer \& Lopez-Boo, 2019) bahwa "across nearly all visits observed, we find strong rapport between teacher and families, and active participation in play-based learning activities introduced by the teacher. Other aspects of home visit design are weakly implemented, namely the revision of topics from previous sessions, demonstration of activities, and dialogue between parent and teacher to practice early stimulation activities".

Home visit ini dijadikan strategi bagi guru yang ada di daerah 3T terkhusus di Kabupaten Sigi sebagai implementasi PAUD dari rumah. Kegiatan home visit yang dilakukan guru merupakan sarana untuk menginformasikan kepada orang tua anak terkait usaha-usaha yang harus dilakukan orang tua dalam mendukung pengembangan seluruh potensi, minat, dan bakat anak secara utuh dan menyeluruh selama di rumah. Orang tua tidak menguasai pengetahuan tentang perkembangan anak sehingga dibutuhkan lembaga yang bisa membantu dalam memberikan stimulus dan memantau tahap perkembangan anak.

Tujuh metode komunikasi yang efektif antara orang tua dan guru menurut (Henniger, 2014) yakni: komunikasi melalui telpon, komunikasi tertulis, komunikasi visual, komunikasi melalui teknologi, pertemuan orang tua, konferensi orang tua dan guru serta kunjungan rumah atau home visit. Selain itu, (Lin \& Bates, 2010) juga mengemukakan bahwa "home visits are an excellent opportunity for teachers to learn about the diverse backgrounds of their students firshand".

Penelitian ini bertujuan untuk menganalisis strategi home visit sebagai bentuk implementasi PAUD dari rumah yang dilakukan oleh guru di daerah 3T pada masa pandemi covid-19. Strategi home visit ini diharapkan dapat terjalin rekonsiliasi antara anak, guru, dan orang tua sehingga anak tetap mendapatkan stimulasi yang tepat selama berada di rumah. Hasil penelitian ini dapat dimanfaatkan oleh tenaga pendidik dan kependidikan dalam mengimplementasi PAUD dari rumah melalui strategi home visit. Selain itu, hasil penelitian ini diharapkan menjadi masukan kepada Pemerintah Daerah terkait ketersediaan sarana dan prasarana penunjang di daerah 3T.

\section{METODOLOGI}

Penelitian ini menggunakan mix method yakni menggabungkan antara penelitian kuantitatif dan kualitatif. Peneliti menggunakan metode kuantitatif dengan instrumen survei untuk melihat berapa banyak guru yang ada di daerah 3T yang menggunakan strategi home visit sebagai implementasi PAUD dari rumah pada masa pandemi covid-19. Kemudian metode kualitatif yang digunakan peneliti bertujuan untuk mendeskripsikan strategi home 
visit yang diterapkan oleh guru PAUD berdasarkan data yang terkumpul. Peneliti melakukan analisis terhadap fakta yang ditemukan untuk menghasilkan informasi (Saghafi \& Mirzaei, 2020). Berikut desain penelitian yang digunakan.

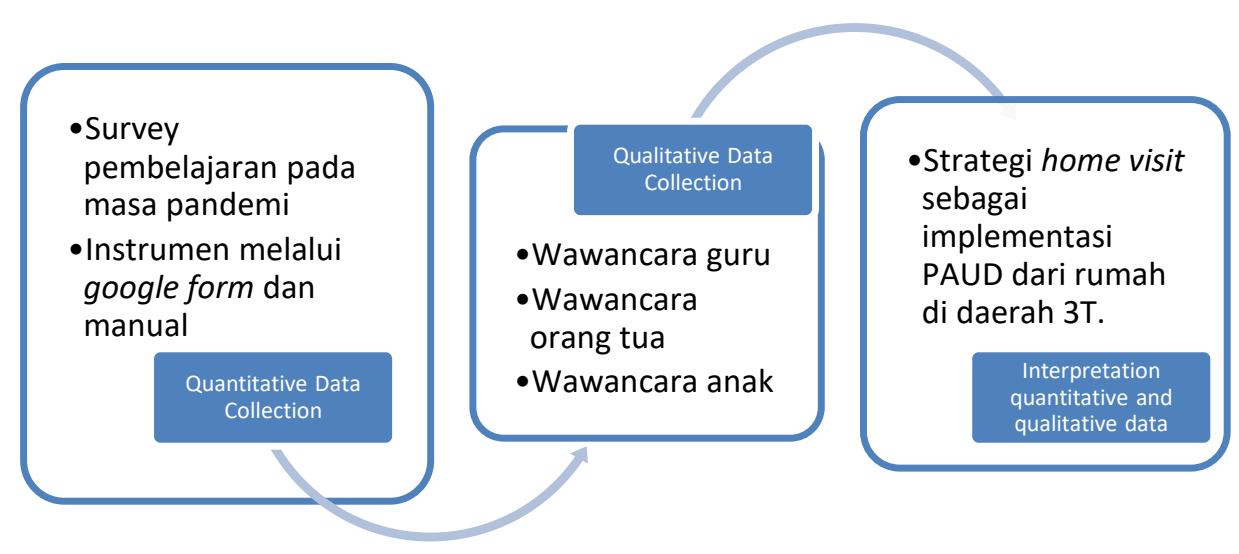

Gambar 1. Desain Penelitian

Penelitian ini dilakukan di Kabupaten Sigi yang termasuk daerah 3T (Terdepan, Terluar, dan Tertinggal). Daerah 3T yang menjadi fokus penelitian ini ada 15 kecamatan yaitu Biromaru, Dolo, Marawola, Kulawi, Kulawi Selatan, Palolo, Dolo Selatan, Dolo Barat, Gumbasa, Lindu, Pipikoro, Tanambulava, Marawola Barat, Nokilalaki, dan Kinovaro. Jumlah responden yakni 235 orang guru yang terdiri dari 201 orang guru TK, 32 orang guru KB, dan 2 orang guru SPS. Teknik pengumpulan data melalui pengisian angket dilakukan dengan dua cara yaitu: 1) dengan menyebarkan link angket yang dibuat melalui google form bagi guru yang memiliki akses internet; dan 2) dengan memberikan angket manual bagi guru yang tidak memiliki akses internet. Selain angket, peneliti juga menggunakan daftar wawancara (Interview Guide) untuk menggali informasi dari guru, orang tua, dan anak terkait strategi home visit yang dilakukan oleh guru. Selain itu, peneliti juga mengumpulkan berbagai dokumentasi dari guru terkait pembelajaran yang telah dilakukan melalui strategi home visit.

Data kuantitatif dianalisis dengan menghitung rerata menggunakan ms. excel yang terlebih dahulu meng-import data dari spreadsheets pada google form ke ms. excel. Sedangkan data kualitatif dianalisis dengan menggunakan metode dari Miles and Huberman yakni reduksi data, penyajian data, verifikasi dan penarikan kesimpulan yang dilakukan pada saat sebelum, saat, dan setelah pengumpulan data, (Colliver, 2016). Uji keabsahan data didasarkan pada empat kriteria yaitu uji kredibilitas, uji transferabilitas, uji dependabilitas, dan uji konfimabilitas, (Colliver, 2016). Selain itu, pengujian keabsahan data juga menggunakan metode triangulasi. Metode triangulasi merupakan sebuah pendekatan untuk memperoleh data yang lebih akurat dengan menggunakan teknik pengumpulan data yang beragam (Roulston, 2018).

Data kualitatif yang dianalisis terkait implementasi strategi home visit yang dilakukan oleh guru selama masa pandemi Covid-19. Peneliti sebagai instrumen utama yang berfungsi memilih informan sumber data, mengumpulkan dan menganalisis data yang diperoleh melalui angket dan hasil wawancara serta melakukan kesimpulan.

\section{HASIL DAN PEMBAHASAN}

Penelitian ini dilakukan mulai tanggal 14 April - 25 Juni 2020. Sebelum menganalisis strategi home visit yang dilakukan oleh guru sebagai implementasi PAUD dari rumah pada masa pandemi Covid-19, peneliti terlebih dahulu melakukan studi eksplorasi dalam bentuk survei untuk mengetahui seberapa banyak guru melakukan pembelajaran dengan kunjungan rumah/home visit. Selain itu, instrumen survei ini juga menggali implementasi pembelajaran dalam jaringan/online seiring dengan adanya kebijakan dari pemerintah terkait belajar dari 
rumah. Berikut hasil penelitian yang menggambarkan persepsi guru terhadap pembelajaran dari rumah pada masa pandemi Covid-19 di daerah 3T.

Tabel 1.1 Survei Pembelajaran dari Rumah di Daerah $3 \mathrm{~T}$

\begin{tabular}{clcccc}
\hline No. & \multicolumn{1}{c}{ Pertanyaan } & \multicolumn{2}{c}{ Ya } & \multicolumn{2}{c}{ Tidak } \\
\cline { 3 - 6 } & \multicolumn{1}{c}{ Frek } & $\mathbf{( \% )}$ & Frek & (\%) \\
\hline 1. & $\begin{array}{l}\text { Apakah guru tahu terkait kebijakan pemerintah untuk } \\
\text { melakukan kegiatan Belajar Dari Rumah (BDR) selama } \\
\text { pandemi covid-19? }\end{array}$ & 221 & 94.0 & 14 & 6.0 \\
\hline 2. & $\begin{array}{l}\text { Apakah guru mengimplementasi pembelajaran dalam } \\
\text { jaringan/online pada anak usia dini? }\end{array}$ & 81 & 34.5 & 154 & 65.5 \\
\hline 3. & $\begin{array}{l}\text { Apakah guru memberikan panduan kepada orang tua } \\
\text { dalam melakukan pendampingan dalam rangka } \\
\text { menstimulasi perkembangan anak di rumah? }\end{array}$ & 126 & 53.6 & 109 & 46.4 \\
\hline 4. & $\begin{array}{l}\text { Apakah guru memberikan tugas kepada anak didik } \\
\text { sebagai bentuk pembelajaran di rumah? }\end{array}$ & 228 & 97.0 & 7 & 3.0 \\
\hline 5. & $\begin{array}{l}\text { Apakah guru melakukan kunjungan ke rumah anak didik } \\
\text { (home visit)? }\end{array}$ & 198 & 84.3 & 37 & 15.7 \\
\hline
\end{tabular}

Berdasarkan tabel hasil survei pembelajaran dari rumah di daerah $3 \mathrm{~T}$ dapat dikemukakan bahwa $94 \%$ dari total responden 235 orang mengetahui kebijakan pemerintah untuk melakukan kegiatan Belajar Dari Rumah (BDR) selama masa pandemi Covid-19. Hal ini menjadi dasar guru untuk memformulasi kegiatan yang akan dilakukan agar proses stimulasi pada anak usia dini tidak terputus selama masa pandemi Covid-19. Sebagai salah satu bentuk BDR sesuai dengan kebijakan pemerintah, sekitar 34,5\% guru mengimplementasikan pembelajaran dalam jaringan/online dan 65,5\% guru tidak mengimplementasikan pembelajaran online tersebut. Rata-rata guru yang mengimplementasikan pembelajaran online berasal dari daerah yang mendapat jaringan yang terletak di ibukota kecamatan seperti Kecamatan Biromaru, Dolo, dan Marawola. Akan tetapi, bagi guru yang tinggal di pelosok diantaranya yaitu: kecamatan Kulawi, Palolo, Dolo Selatan, Dolo Barat, Gumbasa, Lindu, Pipikoro, Tanambulava, Marawola Barat, Nokilalaki, dan Kinovaro tidak melaksanakan pembelajaran online dikarenakan keterbatasan jaringan, listrik, HP android, dan pengetahuan guru dan orang tua terkait IT.

Dilihat dari kompetensinya, guru di daerah 3T masih minim dalam mengoperasikan komputer, mengenal IT, dan menggunakan smartphone sebagai media pembelajaran online. Oleh karena itu, guru-guru tersebut sangat sulit mengimplementasikan pembelajaran dalam jaringan/online kepada anak didik. Hal ini menjadi kendala pada kualitas sumber daya manusia terkait pemanfaatan teknologi dalam proses pembelajaran. Selain itu, faktor ekonomi keluarga yang menjadi faktor utama tidak terlaksananya pembelajaran dalam jaringan ini. Selain itu, guru jarang bahkan tidak pernah mengikuti pembelajaran dengan menggunakan internet/online. Hal tersebut berdasarkan diagram di bawah ini.

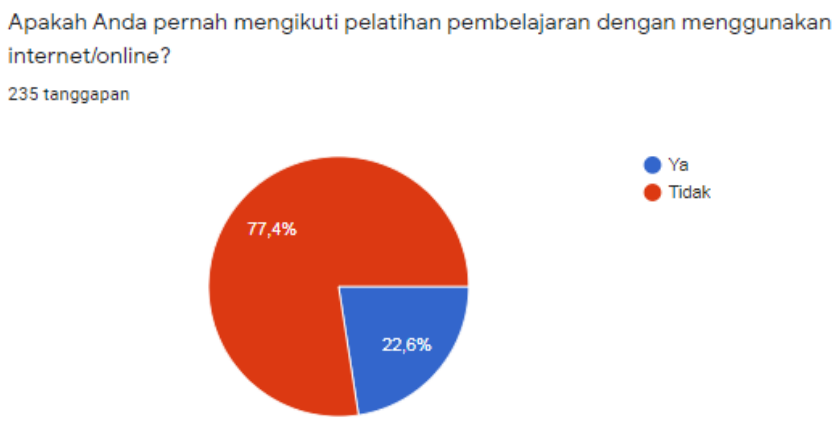

Gambar 2. Persentase Guru dalam Mengikuti Pelatihan Pembelajaran Online 
Walaupun sebesar 38,3\% guru yang ada di daerah 3T memiliki pengalaman mengajar sekitar 11-20 tahun akan tetapi dari segi implementasi pembelajaran online, guru tersebut masih kurang paham dan tidak pernah mengimplementasikan model pembelajaran tersebut. Hal ini juga dilatarbelakangi karena kurangnya daya dukung berupa pelatihan pembelajaran online yang telah diikuti oleh guru. Berdasarkan diagram bahwa sekitar 77,4\% guru tidak pernah mengikuti pelatihan pembelajaran dengan menggunakan internet/online. Belum lagi usia guru di daerah tersebut sudah lanjutan dimana sekitar 36,2\% guru berusia 36-45 tahun dan sekitar 23,4\% guru berusia 45-55 tahun. Hal ini sangat berpengaruh pada kompetensi guru dalam penguasaan teknologi informatika.

Implementasi belajar dari rumah tidak sepenuhnya bisa dijalankan secara maksimal tanpa adanya panduan pembelajaran untuk orang tua. Hal ini berdasarkan tabel 1.1 bahwa sekitar 53,6\% guru memberikan panduan kepada orang tua dalam melakukan pendampingan dalam rangka menstimulasi perkembangan anak di rumah. Panduan ini dibuat sederhana dan mudah diimplementasikan oleh orang tua di rumah. Akan tetapi, ada sekitar $46.4 \%$ guru tidak menggunakan panduan. Berdasarkan hasil wawancara diperoleh data bahwa beberapa guru memberikan SOP, petunjuk teknis, buku aktivitas anak selama di rumah, dan buku paket sesuai tema pembelajaran.

Sekitar 97,0\% guru memberikan tugas kepada anak didik sebagai bentuk pembelajaran di rumah. Ketika dikonfirmasi kepada guru, tugas tersebut tidak menjadi kewajiban anak harus menuntaskan sampai selesai. Akan tetapi, tugas tersebut dikemas dalam bentuk Lembar Kerja Anak (LKA) berupa kegiatan mewarnai, menebalkan garis, menggunting, menempel, menghubungkan, dan lain sebagainya.

Minimnya fasilitas seperti: akses jaringan internet, listrik, kuota, dan android di daerah 3T mengharuskan guru-guru tersebut melakukan strategi home visit atau kunjungan ke rumah-rumah peserta didik agar layanan PAUD tersebut tetap berjalan. Sekitar $84,3 \%$ guru melakukan kunjungan ke rumah anak didik (home visit). Adapun sebaran guru yang melakukan strategi home visit di daerah 3T yaitu sebagai berikut.

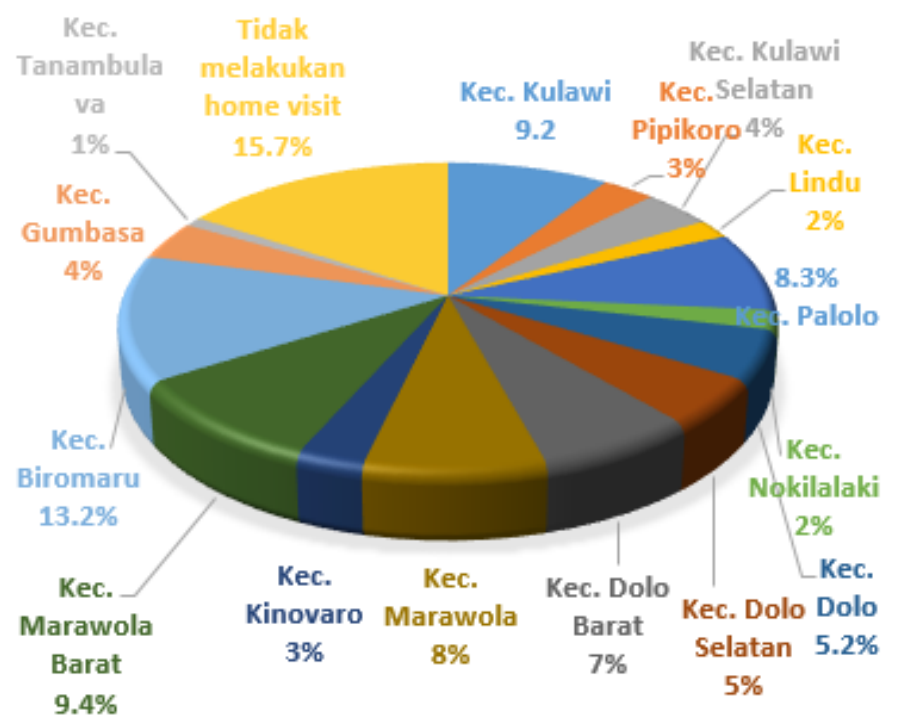

\section{Gambar 2. Persentase Guru yang Melaksanakan Strategi Home Visit di daerah 3T}

Berdasarkan diagram tersebut diperoleh data bahwa dari 235 responden yang mengisi kuesioner baik melalui online maupun manual, terdapat 198 (84,3\%) guru yang melaksanakan strategi home visit sebagai bentuk belajar dari rumah di daerah 3T. Adapun yang paling banyak melaksanakan strategi home visit yaitu guru di Kecamatan Biromaru (13,2\%) dan yang paling sedikit melaksanakan strategi home visit yaitu guru di Kecamatan Tanambulava (1\%). Sedangkan guru yang tidak melakukan strategi home visit sekitar 15,7\%. 
Guru melakukan strategi home visit untuk menjalin komunikasi yang lebih efektif dengan orang tua dan anak. Berdasarkan hasil olah angket, wawancara dan dokumentasi diperoleh data terkait implementasi home visit bagi guru di daerah $3 \mathrm{~T}$ dengan tahapan sebagai berikut.

\section{Tahap Persiapan Home Visit}

Pada tahap persiapan sebelum guru melaksanakan kegiatan home visit, ada beberapa hal yang harus dilakukan yaitu: 1) Guru mengelompokkan anak didik berdasarkan tempat tinggal. Tujuan dari pengelompokan ini agar guru mudah mengimplementasi pelaksanaan BDR melalui strategi home visit. Guru mengelompokkan 3-5 anak yang rumahnya saling berdekatan; 2) Guru membuat jadwal kunjungan setiap kelompok-kelompok anak. Setiap kelompok menerima kunjungan dari guru sebanyak dua kali dalam seminggu secara bergantian dari satu kelompok ke kelompok lain. Setelah mendapatkan pembelajaran melalui home visit dari guru, kemudian hari berikutnya orang tua yang akan melanjutkan kegiatan pembelajaran tersebut di rumah; 3) Guru menghubungi orang tua dan menginformasikan terkait home visit yang akan dilakukan sebagai bentuk BDR pada masa pandemi covid-19. Guru juga menginformasikan bahwa selama pelaksanaan BDR, anak harus mengikuti protokol kesehatan dengan menggunakan masker atau face shield dan mencuci tangan atau menggunakan handsanitizer; 4) Guru menyiapkan RPPH dan panduan pembelajaran. RPPH ini dikemas lebih sederhana dengan menggunakan alat dan bahan bermain yang ada di rumah. Guru juga membuat kegiatan lanjutan yang akan dilaksanakan oleh orang tua di rumah ketika anak tidak sedang belajar kelompok. Kegiatan lanjutan ini juga dikemas sesuai dengan kegiatan yang dilakukan sehari-hari. Guru memberikan panduan pembelajaran kepada orang tua sehingga orang tua mudah mengimplementasikan kegiatan yang akan dilakukan selanjutnya.

\section{Tahap Pelaksanaan Home Visit}

Setelah melakukan perencanaan kegiatan home visit, maka tahap selanjutnya yaitu pelaksanaan home visit yang dilakukan oleh guru dengan melaksanakan kunjungan langsung ke rumah anak yang sudah dikelompokkan sebelumnya. Kegiatan ini berlangsung dari pukul 08.00 sampai 10.00. Kegiatan tersebut dilakukan secara semi formal dimana anak-anak tidak menggunakan seragam. Proses pelaksanaan home visit ini dilakukan sesuai protokol kesehatan pencegahan Covid-19. Anak menggunakan masker dan mencuci tangan sebelum kegiatan dimulai. Pada saat implementasi pembelajaram, orang tua diharapkan terlibat dan melihat langsung proses pembelajaran yang dilaksanakan oleh guru.

Pada kegiatan awal, guru memberikan penjelasan terkait kegiatan yang akan dilaksanakan pada hari itu. Guru juga mendemonstrasikan beberapa kegiatan yang akan dilakukan anak.
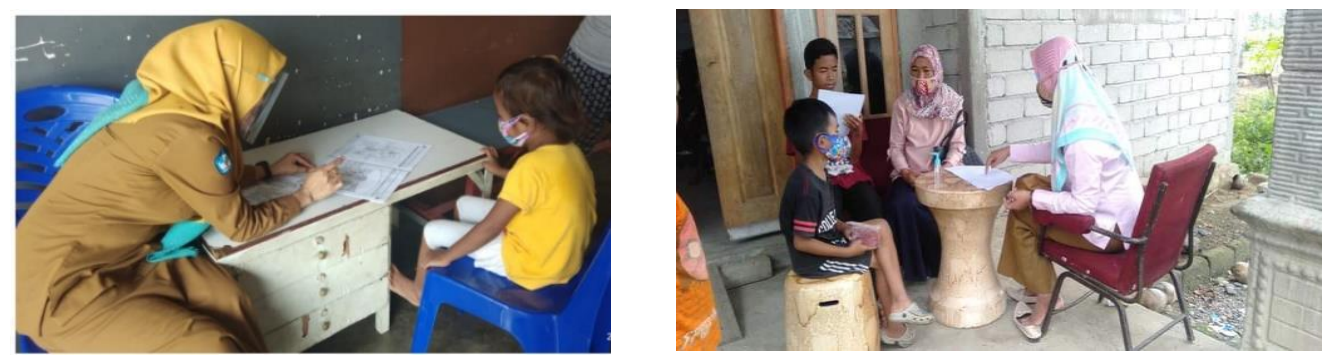

Gambar 1. Pelaksanaan Strategi Home Visit

Guru melakukan strategi home visit ini dua kali dalam seminggu. Visit pertama yaitu memberikan pembelajaran atau kegiatan bermain kepada kelompok anak. Visit kedua yaitu untuk memonitoring kegiatan apa saja yang sudah dilaksanakan dan yang belum dilaksanakan dalam satu minggu. 


\section{Tahap Kegiatan Lanjutan}

Pada tahap kegiatan lanjutan ini dilakukan oleh orang tua di rumah. Orang tua melihat panduan kegiatan yang akan dilaksanakan selama anak di rumah. Kegiatan tersebut tidak harus semuanya dituntaskan tapi disesuaikan dengan kebutuhan, alat dan bahan yang tersedia di rumah. Sebelum dilaksanakan home visit, pemahaman awal orang tua dalam memberikan stimulasi perkembangan anak berada pada kategori rendah. Guru berupaya membuat kelas parenting sesuai dengan kelompok anak untuk memberikan pemahaman kepada orang tua dalam mendidik anak di rumah. Kegiatan parenting ini dilakukan sebulan sekali. Pengembangan pembelajaran anak usia dini sebagai kegiatan lanjutan di rumah yang dilakukan untuk mengembangkan life skill anak (kecakapan hidup, keterampilan, dan pembiasaan). Adapun bentuk kegiatan yakni: merapikan tempat tidur, menggosok gigi, membuat minuman bersama anggota keluarga, menggambar benda-benda yang ada di sekitar rumah, melaksanakan ibadah bersama anggota keluarga, dan lain sebagainya.

\section{Tahap Monitoring dan Evaluasi Pembelajaran}

Pada tahap evaluasi pembelajaran melalui strategi home visit yang dilakukan oleh guru selama masa pandemi Covid-19 yaitu dengan menggunakan teknik checklist. Penilaian dalam bentuk checklist tersebut diberikan seminggu sekali di awal kunjungan. Guru meminta kepada orang tua untuk men-checklist kegiatan apa saja yang sudah terlaksana dan yang belum terlaksana. Pada saat visit kedua, guru melihat kembali kegiatan yang sudah dilaksanakan dan yang belum dilaksanakan oleh guru. Kemudian guru melakukan wawancara dengan orang tua untuk menggali lebih dalam mengenai kegiatan yang sudah dilaksanakan. Guru juga menanyakan kepada orang tua terkait kendala apa saja yang dihadapi selama proses pembelajaran di rumah.

Selama masa pandemi Covid-19, pemerintah mewajibkan agar masyarakat tetap stay at home, work from home, and learning from home. Bagi daerah yang memiliki akses internet dan sarana prasarana yang baik memungkinkan peserta didik bisa belajar dari rumah dengan menggunakan pembelajaran daring/online. Akan tetapi, bagi guru-guru yang ada di daerah 3T memiliki segala keterbatasan dalam mengimplementasikan belajar dari rumah melalui pembelajaran online/daring. Hasil penelitian menunjukkan sekitar 34,5\% guru mengimplementasikan pembelajaran online dan $65,5 \%$ guru tidak mengimplementasikan. Oleh karena itu, guru-guru yang ada di daerah 3T khususnya guru PAUD yang ada di Kabupaten Sigi melakukan proses pembelajaran dengan strategi home visit yakni sekitar 84,3\% atau sekitar 198 orang guru. Hal ini sesuai dengan hasil penelitian (Smith, 2012) yang menyarankan adanya home visit sebagai tindak lanjut dari keterlibatan orang tua di pedesaan dalam rangka mendorong retensi, memberikan pendidikan orang tua, individualisasi layanan dan meningkatkan interaksi orang tua dengan anak.

Proses implementasi pembelajaran melalui strategi home visit ini dilakukan dengan dasar bahwa: 1) minimnya fasilitas yang ada di daerah 3T seperti, listrik, jaringan internet, kuota, HP/smartphone; 2) kompetensi tenaga pendidik dalam mengimplementasikan BDR secara online masih sangat kurang dikarenakan guru-guru tersebut tidak pernah dan tidak terbiasa menggunakan media online dalam pembelajaran; 3 ) sekitar $77,4 \%$ guru tidak pernah mengikuti pelatihan pembelajaran dengan menggunakan internet/online; dan 4) orang tua tidak paham cara menggunakan android. Hal ini juga sesuai dengan beberapa hasil penelitian terkait kendala-kendala yang dihadapi oleh orang tua dalam mendampingi anak belajar di rumah pada masa pandemi covid-19, (Wardani \& Ayriza, 2020; Kurniati et al., 2020).

Implementasi strategi home visit ini diawali dengan perencanaan yang baik. Strategi home visit ini yaitu guru terlebih dahulu mengelompokkan anak kemudian membuat jadwal kunjungan dalam setiap minggunya. Hal ini dilakukan agar guru tetap memberikan layanan dan stimulasi untuk tumbuh kembang anak selama masa pandemi Covid-19. Pada pelaksanaan strategi home visit ini, guru melibatkan orang tua dan membangun komunikasi yang efektif agar orang tua dapat melanjutkan proses pembelajaran selama anak di rumah. Kolaborasi antara guru, orang tua, dan masyarakat sangat penting dalam menyukseskan 
pendidikan dan pengasuhan anak (Gestwicki, 2015; Grant \& Ray, 2010; Irma et al., 2019). Hal ini sesuai dengan penjelasan dari Bustan et al., 2016 bahwa orang tua memiliki peran penting/inti dari tumbuh kembang anak karena anak menghabiskan banyak waktu dengan orang tua untuk saling berinteraksi, berkomunikasi, dan mencurahkan segala perasaan selama kegiatan bermain di rumah (Nahdi et al., 2020; Sulastri \& Tarmizi, 2017). Kegiatan yang disajikan dapat berupa kegiatan yang biasa dilakukan sehari-hari melalui pendekatan integrated curriculum dan integrated activity (Nirmala \& Widartin, 2016). Orang tua dapat menggunakan berbagai alat dan bahan serta permainan tradisional sebagai upaya menstimulasi tingkat pencapaian perkembangan anak (Fauziddin, 2017; Shofyatun \& Nirmala, 2018). Agar suasana lebih menyenangkan, orang tua dan anak dapat melakukan kegiatan gerak dan lagu di awal kegiatan (Agusniatih \& Nirmala, 2020).

Ada beberapa hal yang perlu diperhatikan dalam mengimplementasikan pembelajaran melalui strategi home visit yaitu: 1) guru, orang tua, dan anak harus saling menjaga dan mematuhi protokol kesehatan selama kegiatan berlangsung; 2) kegiatan home visit dijadwalkan sebaik mungkin sehingga mengakomodir semua kelompok anak secara bergiliran; 3) perlunya ada kerja sama yang baik antara guru orang tua; 4) perlunya ada kelas parenting untuk orang tua agar paham cara menstimulasi perkembangan anak; 5) kegiatan berikutnya dilanjutkan oleh orang tua di rumah sehingga walaupun sedang di rumah anak tetap mendapatkan stimulasi yang baik untuk tumbuh kembangnya; 6) melakukan monitoring dan evaluasi, evaluasi proses lebih penting dari pada hasil.

Strategi home visit yang telah diimplementasikan oleh guru-guru di daerah 3T diharapkan dapat memberikan konstribusi bagi dunia pendidikan khususnya pendidikan anak usia dini. Strategi pembelajaran ini juga diharapkan dapat memfasilitasi anak PAUD di daerah 3T dengan segala keterbatasan demi tetap memberikan layanan dan stimulasi yang baik pada masa pandemi Covid-19. Selain itu, home visit memberikan pengaruh yang positif dalam mengembangkan perilaku anak, meningkatkan motivasi, prestasi belajar dan meningkatkan kemampuan orang tua dalam menstimulasi perkembangan anak (Wright et al., 2018; Meyer \& Mann, 2006). Strategi home visit ini juga dapat memperluas dan meratakan akses pendidikan anak usia dini untuk seluruh anak di Indonesia yang berasal dari berbagai latar belakang ekonomi, sosial, budaya, dan adat istiadat (Komalasari, 2016).

\section{SIMPULAN}

Pelaksanaan BDR masih sulit dilaksanakan dengan menggunakan pembelajaran daring. Sekitar $65,5 \%$ guru tidak mengimplementasikan pembelajaran daring pada masa pandemi. Hal ini karena di daerah 3T minim fasilitas dan sumber daya manusia. Salah satu strategi bagi guru PAUD yaitu home visit dalam bentuk kelompok belajar (84,3\%). Adapun yang paling banyak melaksanakan strategi home visit yaitu guru di Kecamatan Biromaru $(13,2 \%)$ dan yang paling sedikit di Kecamatan Tanambulava (1\%). Ada empat tahapan strategi home visit yakni: 1) tahap persiapan; 2) tahap pelaksanaan; 3) tahap kegiatan lanjutan; dan 4) monitoring dan evaluasi. Diharapkan strategi home visit menjadi solusi bagi guru PAUD dengan segala keterbatasan untuk tetap memberikan layanan yang terbaik di daerah 3T.

\section{UCAPAN TERIMA KASIH}

Pertama, penulis memanjatkan puji syukur atas kehadirat Allah SWT atas rahmat dan karunia-Nya sehingga penulis dapat menyelesaikan artikel ini. Penulis mengucapkan terima kasih yang sebesar-besarnya kepada seluruh pihak yang terlibat selama proses penelitian dan penyusunan artikel ini. Terima kasih kepada kepala TK dan guru-guru PAUD yang ada di Kabupaten Sigi, tim peneliti, mahasiswa PG PAUD Untad dan mahasiswa UT Palu yang telah membantu peneliti dalam mengumpulkan data. Terakhir penulis juga sampaikan kepada pengelola dan tim reviewer Jurnal Obsesi yang telah memberikan kesempatan sehingga artikel ini dapat dipublikasikan. 


\section{DAFTAR PUSTAKA}

Agus Purwanto*, Rudy Pramono, Masduki Asbari, Priyono Budi Santoso, Laksmi Mayesti Wijayanti, Choi Chi Hyun, R. S. P. (2017). Studi Eksploratif Dampak Pandemi COVID19 Terhadap Proses Pembelajaran Online di Sekolah Dasar. EduPsyCouns: Journal of Education, Psychology and Counseling, 2(1), 165-170.

Agusniatih, A., \& Nirmala, B. (2020). Development of Motion Creativity and Songs for Stimulating Children's Social Emotional at Kindergarten in Palu Sulawesi. International Conference of Early Childhood Education (ICECE 2019), 173-177. https://doi.org/10.2991/assehr.k.200715.036

Colliver, Y. (2016). Mothers' Perspectives on learning through Play in the Home. Australasian Journal of Early Childhood, 41(1), 4-12. https:/ / doi.org/10.1177/183693911604100102

Fauziddin, M., \& others. (2017). PENERAPAN BELAJAR MELALUI BERMAIN DALAM MENINGKATKAN KREATIVITAS ANAK USIA DINI. Jurnal Curricula, 1(3). https://doi.org/10.22216/jcc.2016.v2i3.1277

Gestwicki, C. (2015). Home, School, and Community Relations. CT: Cengage Learning.

Grant, K. B., \& Ray, J. A. (2010). Home, school, and community collaboration: Culturally responsive family involvement. In Home, school, and community collaboration: Culturally responsive family involvement. Sage Publications. https://www.lib.uwo.ca/cgibin/ezpauthn.cgi?url=http://search.proquest.com/docview/621557025?accountid=1 5115\%0Ahttp://vr2pk9sx9w.search.serialssolutions.com?ctx_ver=Z39.882004\&ctx_enc=info:ofi/enc:UTF-

$8 \&$ rfr_id=info:sid/PsycINFO+\&rft_val_fmt=info:ofi/fmt:ke

Henniger, M. L. (2014). Teaching Young Children: An Introduction 5th Edition. Merrill Ohio. https://www.pearson.com/us/higher-education/program/Henniger-TeachingYoung-Children-An-Introduction-with-Enhanced-Pearson-e-Text-Access-CardPackage-6th-Edition/PGM214033.html

Ilhan, F., Ozfidan, B., \& Yilmaz, S. (2019). Home visit effectiveness on students' classroom behavior and academic achievement. Journal of Social Studies Education Research, 10(1), 61-80.

Irma, C. N., Nisa, K., \& Sururiyah, S. K. (2019). Keterlibatan Orang Tua dalam Pendidikan Anak Usia Dini di TK Masyithoh 1 Purworejo. Jurnal Obsesi : Jurnal Pendidikan Anak Usia Dini, 3(1), 214-224. https:// doi.org/10.31004/obsesi.v3i1.152

Mekanisme Pembelajaran dan Penilaian Madrasah dalam Masa Darurat Pencegahan Penyebaran Covid-19, https://doi.org/https:/ / doi.org/10.1016/j.compcom.2018.05.003

Komalasari, E. (2016). Layanan Home Visit Pendidikan Anak Usia Dini Bagi Anak Kurang Sejahtera. Ta'dib, 18(1), 76-85.

Kurniati, E., Nur Alfaeni, D. K., \& Andriani, F. (2020). Analisis Peran Orang Tua dalam Mendampingi Anak di Masa Pandemi Covid-19. Jurnal Obsesi : Jurnal Pendidikan Anak Usia Dini, 5(1), 241. https://doi.org/10.31004/obsesi.v5i1.541

Leer, J., \& Lopez-Boo, F. (2019). Assessing the quality of home visit parenting programs in Latin America and the Caribbean. Early Child Development and Care, 189(13), 2183-2196. https://doi.org/10.1080/03004430.2018.1443922

Lin, M., \& Bates, A. B. (2010). Home Visits: How Do They Affect Teachers' Beliefs about Teaching and Diversity? Early Childhood Education Journal, 38(3), 179-185. https:/ / doi.org/10.1007/s10643-010-0393-1

Menteri Pendidikan dan Kebudayaan. (2020). Pelaksanaan Kebijakan Pendidikan Dalam Masa Darurat Penyebaran Coronavirus Disease (COVID-19). In Jakarta: Kementerian Pendidikan dan Kebudayaan.

Meyer, J. A., \& Mann, M. B. (2006). Teachers' perceptions of the benefits of home visits for early elementary children. Early Childhood Education Journal, 34(1), 93-97.

Nahdi, K., Ramdhani, S., Yuliatin, R. R., \& Hadi, Y. A. (2020). Implementasi Pembelajaran pada 
Masa Lockdown bagi Lembaga PAUD di Kabupaten Lombok Timur. Jurnal Obsesi : Jurnal Pendidikan Anak Usia Dini, 5(1), 177. https:/ / doi.org/10.31004/obsesi.v5i1.529

Nirmala, B., \& Widartin, T. (2016). Model PAUD Full Day School yang Menyenangkan dan Implementasinya. PROSIDING, 46.

Nugracha, H. (2019). Sembilan Daerah di Sulteng Masih Tertinggal. Suara Palu: Https:/Suarapalu.Com/Sembilan-Daerah-Di-Sulteng-Masih-Tertinggal/.

Nurkolis, N., \& Muhdi, M. (2020). Keefektivan Kebijakan E-Learning berbasis Sosial Media pada PAUD di Masa Pandemi Covid-19. Jurnal Obsesi : Jurnal Pendidikan Anak Usia Dini, 5(1), 212. https://doi.org/10.31004/obsesi.v5i1.535

Putra, M. T. F., \& Rhussary, M. L. (2014). Peningkatan Mutu Pendidikan Daerah 3t (Terdepan, Terpencil dan Tertinggal) di Kabupaten Mahakam Hulu. Jurnal Ekonomi Dan Manajemen, 12(2), 144-148. https://www.neliti.com/publications/284861/peningkatan-mutu-pendidikandaerah-3t-terdepanterpencil-dan-tertinggal-di-kabupa

Roulston, K. (2018). Triangulation in qualitative research. Retrieved From.

Saghafi, M. R., \& Mirzaei, B. (2020). The spatial configuration analysis of a high school through a participatory approach. Architectural Engineering and Design Management, 1-19. https:/ / doi.org/10.1080/17452007.2020.1744420

Shereen, M. A., Khan, S., Kazmi, A., Bashir, N., \& Siddique, R. (2020). COVID-19 infection: Origin, transmission, and characteristics of human coronaviruses. In Journal of Advanced Research (Vol. 24, pp. 91-98). Elsevier. https:// doi.org/10.1016/j.jare.2020.03.005

Shi, H., Han, X., Jiang, N., Cao, Y., Alwalid, O., Gu, J., Fan, Y., \& Zheng, C. (2020). Radiological findings from 81 patients with COVID-19 pneumonia in Wuhan, China: a descriptive study. The Lancet Infectious Diseases, 20(4), 425-434. https://doi.org/10.1016/S14733099(20)30086-4

Shofyatun, A. R., \& Nirmala, B. (2018). Permainan Tradisional Sebagai Upaya Menstimulasi Tingkat Pencapaian Perkembangan Anak Usia Dini. Early Childhood Education Journal of Indonesia, 1(2), 31-38.

Smith, J. A. (2012). Parents' and parent educators' understandings of the Parents as Teachers home visiting program in a small rural, Mid-west community [University of Missouri-Columbia]. In ProQuest Dissertations and Theses. https:// doi.org/https:/ / doi.org/10.32469/10355/15903

Sohrabi, C., Alsafi, Z., O'Neill, N., Khan, M., Kerwan, A., Al-Jabir, A., Iosifidis, C., \& Agha, R. (2020). World Health Organization declares global emergency: A review of the 2019 novel coronavirus (COVID-19). In International Journal of Surgery (pp. 76, 71-76). Elsevier.

Sulastri, S., \& Ahmad Tarmizi, A. T. (2017). Peran Orang Tua Dalam Pendidikan Anak Usia Dini. Raudhatul Athfal: Jurnal Pendidikan Islam Anak Usia Dini, 1(1), 61-80. https:// doi.org/10.19109/ra.v1i1.1526

Sun, L., Tang, Y., \& Zuo, W. (2020). Coronavirus pushes education online. In Nature Materials (Vol. 19, Issue 6, p. 687). Nature Publishing Group. https://doi.org/10.1038/s41563020-0678-8

Wardani, A., \& Ayriza, Y. (2020). Analisis Kendala Orang Tua dalam Mendampingi Anak Belajar di Rumah Pada Masa Pandemi Covid-19. Jurnal Obsesi : Jurnal Pendidikan Anak Usia Dini, 5(1), 772. https:// doi.org/10.31004/obsesi.v5i1.705

Wright, K., Shields, S., Black, K., \& Waxman, H. (2018). The Effects of Teacher Home Visits on Student Behavior, Student Academic Achievement, and Parent Involvement. School Community Journal, 28(1), 67.

Wulandari, H., \& Purwanta, E. (2021). Pencapaian Perkembangan Anak Usia Dini di TK selama Pembelajaran Daring saat Pandemi Covid-19. Jurnal Obsesi : Jurnal Pendidikan Anak Usia Dini, 5(1), 452-462. https://doi.org/10.31004/obsesi.v5i1.626 